\title{
Residência médica de pediatria: Limites e possibilidades
}

\author{
Pediatric medical residency: Limits and possibilities \\ Residencia médica pediátrica: Límites y posibilidades
}

Recebido: 09/04/2021 | Revisado: 16/04/2021 | Aceito: 19/04/2021 | Publicado: 04/05/2021

\author{
Ianik Rafaela Leal de Albuquerque \\ ORCID: https://orcid.org/0000-0001-5404-949X \\ Universidade CEUMA, Brasil \\ E-mailianikleal@yahoo.com.br \\ Maria Raimunda Chagas Silva \\ ORCID: https://orcid.org/0000-0002-8685-7608 \\ Universidade CEUMA, Brasil \\ E-mail: marirah@gmail.com \\ Flor De Maria Araújo Mendonça Silva \\ ORCID: https://orcid.org/0000-0002-2796-0939 \\ Universidade CEUMA, Brasil \\ E-mail: floragyhn@gmail.com \\ Marcos Antônio Barbosa Pacheco \\ ORCID: https://orcid.org/0000-0002-3566-5462 \\ Universidade CEUMA, Brasil \\ E-mail: mmmarco@terra.com.br \\ Claudia Barbastefano Monteiro \\ ORCID: https://orcid.org/0000-0002-3150-7424 \\ Universidade Federal do Rio de Janeiro, Brasil \\ E-mail: claudia.ipub@gmail.com \\ Cristina Maria Douat Loyola \\ ORCID: https://orcid.org/0000-0003-2824-6531 \\ Universidade CEUMA, Brasil \\ E-mail: crisloyola@hotmail.com
}

\begin{abstract}
Resumo
A Pós-Graduação em Medicina é uma etapa peculiar na Educação Médica, tendo na Residência Médica sua forma de especialização de caráter regular e permanente, e considerada padrão ouro na formação do médico. O estado do Maranhão tem uma das médias mais baixas, no que tange à relação profissionais médicos para cada grupo de mil pessoas. Em 2016 foi implementada a residência em Pediatria na rede estadual de saúde e buscamos através deste trabalho compreender a percepção dos médicos, residentes em Pediatria e preceptores, acerca de sua experiência nesse Programa de Residência Médica. Trata-se de um estudo descritivo e analítico, com abordagem qualitativa, e utilizamos como método para coleta de dados a entrevista semiestruturada onde entrevistamos 7 residentes e 13 preceptores. A pesquisa foi realizada de maio de 2019 a março de 2020, em um hospital de referência em Pediatria da rede estadual. Os resultados reafirmam a importância da residência médica, bem como apontam para a necessidade de redimensionamento da política de preceptoria médica da Secretaria de Saúde do Estado, no que se refere principalmente a importância de protocolos clínicos nos hospitais da rede, educação continuada na formação de médicos preceptores, revisão de contratos com grupos médicos que incluam a responsabilidade quanto à preceptoria médica, implementação de processo de avaliação de preceptores e definição de suas competências pedagógicas e responsabilidades técnicas.
\end{abstract}

Palavras-chave: Pós-graduação; Residência médica; Pediatria; Saúde; Ensino.

\begin{abstract}
The Post-Graduation in Medicine is a peculiar step in Medical Education, having in the Medical Residency its form of specialization of a regular and permanent character, and considered the gold standard in the training of doctors. The state of Maranhão has one of the lowest averages, with respect to the ratio of medical professionals for each group of one thousand people. In 2016, the residency in Pediatrics was implemented in the state health network and we seek through this work to understand the perception of doctors, residents in Pediatrics and preceptors, about their experience in this Medical Residency Program. This is a descriptive and analytical study, with a qualitative approach, and we used the semi-structured interview as a method for data collection where we interviewed 7 residents and 13 preceptors. The research was carried out from May 2019 to March 2020, in a state referral hospital in Pediatrics. The results reaffirm the importance of medical residency, as well as pointing to the need to redimension the policy of medical preceptorship of the State Health Secretariat, with regard mainly to the importance of clinical protocols in network hospitals, continuing education in the training of doctors preceptors, review of contracts with medical groups
\end{abstract}


that include responsibility for medical preceptorship, implementation of a preceptor assessment process and definition of their pedagogical skills and technical responsibilities.

Keywords: Postgraduate studies; Medical residence; Pediatrics; Health; Teaching.

\section{Resumen}

El Posgrado en Medicina es un paso peculiar en la Educación Médica, teniendo en la Residencia Médica su modalidad de especialización de carácter regular y permanente, y considerada el patrón oro en la formación de médicos. El estado de Maranhão tiene uno de los promedios más bajos, con respecto a la proporción de profesionales médicos por cada grupo de mil personas. En 2016 se implementó la residencia en Pediatría en la red de salud estatal y buscamos a través de este trabajo comprender la percepción de médicos, residentes en Pediatría y preceptores, sobre su experiencia en este Programa de Residencia Médica. Se trata de un estudio descriptivo y analítico, con enfoque cualitativo, y utilizamos la entrevista semiestructurada como método de recolección de datos, donde entrevistamos a 7 residentes y 13 preceptores. La investigación se llevó a cabo desde mayo de 2019 hasta marzo de 2020, en un hospital de referencia estatal en Pediatría. Los resultados reafirman la importancia de la residencia médica, además de señalar la necesidad de redimensionar la política de preceptoría médica del Departamento de Salud del Estado, con respecto principalmente a la importancia de los protocolos clínicos en los hospitales de la red, la educación continua en la formación de médicos preceptores, la revisión de contratos con grupos médicos que incluyan la responsabilidad cuanto a la preceptoría médica, la implementación de un proceso de evaluación del preceptor y la definición de sus competencias pedagógicas y responsabilidades técnicas.

Palabras clave: Posgrado; Residencia médica; Pediatría; Salud; Ensenãnza.

\section{Introdução}

O foco desse artigo é compreender a percepção dos médicos residentes e preceptores acerca de suas experiências no Programa de Residência Médica em Pediatria.

Muitos países convivem atualmente com crises e desafios relacionados à oferta, distribuição, formação, remuneração e ao desempenho de profissionais médicos (Scheffer, Cassenote, Poz, Matijasevitch, \& Castilho, 2015; World Health Organization, 2008).

Em relação a formação médica, a Residência Médica (RM) é o padrão ouro da formação nessa área, tendo sido instituída pelo Decreto $\mathrm{n}^{\circ}$ 80.281, de 5 de setembro de 1977 e devendo funcionar em instituições de saúde, sob a orientação de profissionais médicos de elevada qualificação ética e profissional. A RM é um programa de treinamento em serviço, de longa duração, reconhecido como o melhor mecanismo de capacitação de médicos para o exercício profissional especializado, responsável e de qualidade (Fernandes et al., 2015).

Esse sistema de especialização em Medicina, sob a forma de Residência, é creditado a William Halstedt, médico americano, a partir de 1889, no departamento de Cirurgia da Universidade de John's Hopkins (Fernandes et al., 2015).

No Brasil, a modalidade RM iniciou-se na década de 1940, com a criação dos primeiros programas para suprir a necessidade de aprimoramento das competências dos profissionais atendendo à demanda do mercado de trabalho, que se tornava competitivo. No final da década de 1960 e na década de 1970, o aumento do número de cursos de Medicina no país ocasionou a expansão dos programas de RM, que passaram a ser amplamente procurados por profissionais egressos das escolas médicas (Teixeira et al., 2017).

A preocupação pela formação de profissionais bem qualificados sempre existiu no âmbito do Sistema Único de Saúde (SUS). Coube à Constituição Federal de 1988, por meio do artigo 200, explicitar ao SUS a incumbência de "ordenar a formação de recursos na área da saúde" (Brasil, 1988).

A promulgação da Lei Orgânica de Saúde n 8.080 estabeleceu para as três esferas de governo a "participação na formulação e na execução da política de formação e desenvolvimento de recursos humanos para a saúde" e a "organização de um sistema de formação de recursos humanos em todos os níveis de ensino, inclusive de pós-graduação, além da elaboração de programas de permanente aperfeiçoamento de pessoal". Determinou ainda que "os serviços públicos que integram o SUS 
constituem campo de práticas para ensino e pesquisa, respeitando normas específicas, elaboradas conjuntamente com o sistema educacional" (Brasil, 1990).

No estado do Maranhão, identificamos grande atraso quanto à oferta de vagas para a formação médica especializada, haja vista as residências médicas terem sido implementadas apenas na década de 1980, inicialmente nos Hospitais Presidente Dutra e Materno Infantil, então administrados pelo extinto Instituto Nacional de Assistência Médica da Previdência Social (Inamps). Os programas credenciados na época foram: Clínica Médica, Medicina Geral e Comunitária, Cirurgia Geral, GinecoObstetrícia e Pediatria.

A implementação da modalidade de RM na rede Estadual de saúde, sofreu um atraso ainda maior. O início dos Programas de RM da Secretaria de Estado da Saúde do Maranhão (SES-MA) deu-se no ano de 2009, no Hospital "Tarquínio Lopes Filho" (Hospital Geral) com os Programas de RM em Cirurgia Geral e Clínica Médica. E por fim, a RM de Pediatria só foi instituída na rede estadual de saúde do Maranhão a partir do ano de 2016, no Hospital Juvêncio Mattos, inicialmente com 2 vagas.

O Maranhão tem um total 6.096 médicos registrados, para mais de 7 milhões de habitantes, o que corresponde a 0,87 profissionais para cada grupo de mil pessoas. Desse total de médicos, 71,9\% encontra-se na capital São Luís, e temos um registro total de 464 Pediatras para todo o Estado e podemos dizer que este quadro é preocupante (Scheffer et al., 2015).

Esses números chamam nossa atenção por duas questões: um baixo quantitativo de Pediatras no Estado e uma baixa cobertura por essa especialidade nos interiores. Isso pode ter reflexo em dados importantes, como um dos maiores índices de mortalidade infantil do Brasil: o Maranhão apresentou o coeficiente 16,1 óbitos por 1.000 nascidos vivos (Ceccon et al., 2014).

Diante desses dados, nos perguntamos: como se dá a formação do Pediatra num Estado com essa realidade? As políticas públicas do nosso Estado enxergam a necessidade de profissionais bem treinados para atender essas necessidades? A residência em pediatria vem formando especialistas para atuar nessa realidade? Qual a percepção de alunos e preceptores quanto a esta realidade?

Cabe destacar ainda que o número de médicos especialistas titulados aumentou no Brasil, entre as 53 especialidades reconhecidas e há evidências de que o crescimento do efetivo de médicos com especialização está ligado à melhoria da captação de dados, ou seja, aumento no número de registros desses médicos especializados, mas também pode ser reflexo das políticas de expansão de programas e vagas de RM (Scheffer et al., 2015).

O objetivo de universalizar o acesso à RM para todos os graduados em Medicina, exigiu uma meta de criação de 12,4 mil vagas para a formação de especialistas até 2018, e requereu a formação de preceptores, onde o Ministério da Saúde pretendia formar 10 mil preceptores até 2018, alcançando a meta de 12,4 mil profissionais, capazes de supervisionar até 3 residentes, média considerada ideal para o processo de ensino-aprendizagem na residência médica e podendo, ainda, atuar junto aos graduandos (Petta, Lima, Oliveira, \& Gomes, 2017).

Seguindo essa tendência de ampliação dos serviços da RM, em 2019, através da Lei no 11.114 de 2 de outubro, o estado do Maranhão institui a Escola de Saúde Pública, unidade administrativa integrante da estrutura da Secretaria de Estado da Saúde. Nessa mesma lei foram criados o Programa INOVA e o Programa estadual de Bolsas de Estudo, Pesquisa e Extensão. A Escola de Saúde Pública, atuando frente às áreas de interesse do SUS, têm como competências desenvolver programas de capacitação, residências médicas, formar trabalhadores na área de saúde, de forma inicial e continuada, promover a integração entre ensino, serviço e comunidade garantir a pesquisa cientifica e a inovação tecnológica, dentre outros aspectos ligados à melhoria, eficácia e promoção dos serviços de saúde pública (Maranhão, 2019).

As Diretrizes Curriculares Nacionais do Curso de Graduação em Medicina, publicada em junho de 2014, requereram das escolas médicas uma mudança nos seus projetos pedagógicos, ampliando o potencial de induzir um novo paradigma na formação de profissionais médicos no país (Petta et al., 2017). 
O médico a ser formado precisa compreender a realidade populacional brasileira, aquela que é atendida pelo maior convênio de saúde de todos os tempos: o SUS. E a formação do médico residente também compete compreender esta realidade. Ambos, os médicos e os residentes, no geral, são formados no SUS, diante de muitas dificuldades de estrutura, às vezes sem fluxo de trabalho definido, mas diante de uma população que necessita de cuidados de saúde. Será que a formação do profissional médico está sendo direcionada para resolução dos problemas dos pacientes que buscam o SUS?

Segundo o art. $7^{\circ}$ das Diretrizes Curriculares Nacionais do Curso de Graduação em Medicina, são objetivos previstos para a educação dos médicos: aprender a aprender, como parte do processo de ensino-aprendizagem, identificando conhecimentos prévios, desenvolvendo a curiosidade e formulando questões para a busca de respostas cientificamente consolidadas, construindo sentidos para a identidade profissional e avaliando, criticamente, as informações obtidas, preservando a privacidade das fontes; aprender com autonomia e com a percepção da necessidade da educação continuada, a partir da mediação dos professores e profissionais do Sistema Único de Saúde, desde o primeiro ano do curso; aprender interprofissionalmente, com base na reflexão sobre a própria prática e pela troca de saberes com profissionais da área da saúde e outras áreas do conhecimento, para a orientação da identificação e discussão dos problemas, estimulando o aprimoramento da colaboração e da qualidade da atenção à saúde e aprender em situações e ambientes protegidos e controlados, ou em simulações da realidade, identificando e avaliando o erro, como insumo da aprendizagem profissional e organizacional e como suporte pedagógico (Brasil, 2014).

Diante do contexto apresentado, considerando a realidade do estado do Maranhão na formação de médicos, inclusive os especialistas, e considerando nossa responsabilidade individual à frente da RM em Pediatria da rede Estadual do Maranhão, nos propomos a compreender a percepção dos médicos residente em Pediatria e dos médicos preceptores do serviço, quanto às potencialidades e desafios encontrados nesta modalidade de especialização.

A elaboração deste projeto de pesquisa nos possibilitou a inserção num espaço de aprendizagem propício à reflexão. A troca de saberes com profissionais da área da saúde, e também de outras áreas do conhecimento favoreceu significativamente nosso processo de aprendizagem.

Nesse espaço de troca de conhecimentos, surgiram, através das nossas observações empíricas, os primeiros questionamentos sobre os desafios enfrentados pelos residentes nesse processo. Como seria possível compreender melhor esse espaço? Em que sentido, discutir os limites e as potencialidades da residência médica poderia contribuir para novas proposições e aprimoramentos nesse campo? Os processos de trabalho relacionados à preceptoria se coadunam com qual concepção de formação/qualificação profissional? Quais concepções norteiam as práticas dos residentes ao longo dos programas de RM?

Diante do exposto, justificou-se a necessidade de uma melhor análise da percepção dos residentes e preceptores acerca dos limites e potencialidades do programa de RM em pediatria na rede estadual de saúde do Maranhão, afim de contribuirmos com a ampliação da discussão sobre o tema.

\section{Metodologia}

Realizou-se uma pesquisa qualitativa, descritiva e analítica, com análise de conteúdo na modalidade temática, para compreender criticamente o contexto do objeto de estudo: a percepção dos residentes e dos preceptores acerca de suas experiências no Programa de Residência Médica em Pediatria.

O estudo ocorreu de maio de 2019 a março de 2020, em uma capital do Nordeste brasileiro, também componente da região da Amazônia legal, em um hospital público estadual referência em pediatria, exclusivo do SUS, onde foi implementada a especialização na modalidade residência médica desde 2016. Neste hospital os atendimentos ocorrem ambulatorialmente com consultas pré-agendadas e nas enfermarias e unidades de terapia intensiva (UTIs) pediátrica e neonatal. O rodizio dos 
residentes se completa na rede do Estado, nas unidades de pronto atendimento (UPAs) - atendimento de urgência e emergência e na Maternidade de Alta Complexidade (UTI Neonatal e sala de parto).

Os sujeitos da pesquisa foram médicos residentes e médicos preceptores da residência médica em pediatria nesse hospital, local de estudo. Utilizou-se como critérios de inclusão estar cursando a RM de Pediatria da SES-MA há pelo menos 6 meses; ter cursado a RM em pediatria no hospital campo de pesquisa; ser médico preceptor no serviço onde se realiza a Residência de Pediatria há pelo menos 1 ano; ter sido médico preceptor no serviço de Pediatria onde se realiza a residência por pelo menos 6 meses.

Foram excluídos os médicos residentes ou preceptores que tenham se desligado do serviço, que estivessem usufruindo de férias ou licença durante o tempo da pesquisa.

Foi utilizada amostragem por saturação teórica, através da inclusão progressiva, para estabelecer o tamanho final da amostra. Dessa forma, não houve demarcação antecipada do número de participantes, sendo a quantidade definida mediante a verificação da regularidade da apresentação de ideias, explicações e sentidos atribuídos pelos entrevistados (Minayo, 2014).

A pesquisa incluiu 20 entrevistas, sendo 7 residentes e 13 preceptores. Obtivemos início da repetição de respostas em torno da quinta entrevista de médicos residentes (de um total de 7 residentes no serviço aptos a participarem da pesquisa); e obtivemos saturação na décima entrevista de preceptores (de um total de 13 entrevistados). Devido à pandemia da Covid-19 tivemos dificuldade em aumentar o número de entrevistas entre os médicos residentes e preceptores.

Os instrumentos para a coleta de dados foram o Questionário de Dados Sociodemográficos e os Roteiro de Entrevista Semiestruturada para os médicos residentes e médicos preceptores. O questionário sociodemográfico foi utilizado para melhor compreensão do contexto socioeconômico do indivíduo analisado.

O local da entrevista atendeu à escolha dos entrevistados. As entrevistas foram gravadas com dispositivos eletrônicos de áudio, sendo posteriormente transcritas pela autora.

Após transcrição, foi realizada a análise de conteúdo na modalidade temática, que teve por objetivo compreender a percepção dos residentes e dos preceptores acerca de suas experiências no Programa de Residência Médica em Pediatria.

Segundo as orientações de Minayo, a análise temática de conteúdo foi realizada em três etapas. A pré-análise que consistiu na escolha dos documentos a serem analisados, a retomada de hipóteses e de objetivos da pesquisa - reformulando-os frente ao material coletado -, e a elaboração de indicadores que orientassem a interpretação final (Minayo, 2014).

A exploração do material - ou codificação - caracterizou-se pela transformação dos dados brutos em elementos interpretáveis, pretendendo alcançar o núcleo de compreensão do texto. Finalmente, o tratamento dos resultados obtidos - ou interpretação - baseou-se na proposição de inferências e na realização de interpretações previstas no referencial teórico. Todos os nomes originais que surgiram nas entrevistas foram substituídos por nomes fictícios. Os entrevistados, neste artigo, foram codificados de 1 a 7 entre os residentes (identificados com a letra "R" variando de R1 a R7), e de 1 a 13 entre os preceptores (identificados com a letra "P", variando de P1 a P13).

A análise temática de conteúdo transcende a tecnicidade do processo, porquanto abrange uma investigação histórica, teórico-prática, no âmbito do reconhecimento social (Minayo, 2013).

Este estudo teve alicerce na Resolução n 466/1240 do Conselho Nacional de Saúde (CNS), que regulamenta as pesquisas envolvendo seres humanos. Todos os participantes foram devidamente informados e esclarecidos quanto à importância e ao objetivo da pesquisa, bem como seus riscos - como constrangimento - e benefícios - como possibilidade de intervenções futuras de capacitação.

O Termo de Consentimento Livre e Esclarecido foi assinado por todos os entrevistados. Foram garantidos a possibilidade de não participação ou desistência na pesquisa, a privacidade, a confiabilidade e o anonimato dos participantes. Esta pesquisa foi aprovada pelo Comitê de Ética em Pesquisa com Seres Humanos da Universidade Ceuma (Uniceuma) através 
do Parecer Consubstanciado no 3.306.301 em 07 de maio de 2019, com Certificado de Apresentação para Apreciação Ética (CAAE) $n^{\circ} 08482519.8 .0000 .5084$.

Foram realizadas 20 entrevistas, sendo 7 médicos residentes, e 13 médicos preceptores.

Em relação ao perfil sociodemográfico dos residentes, houve predominância do sexo feminino; a idade variou entre 28 e 34 anos; a maioria se declarou casado ou em união estável; todos os entrevistados se formaram em faculdades no estado do Maranhão, seja pública ou privada; 5 entrevistados são naturais do Maranhão, e os outros entrevistados são provenientes de outros estados; dos entrevistados provenientes de outros estados, apenas 1 afirmou que voltaria para sua terra natal.

Em relação ao perfil sociodemográfico dos preceptores, houve predominância do sexo feminino; a idade variou entre 32 e 50 anos; a maioria se declarou casado ou em união estável; todos os entrevistados se formaram em faculdades no estado do Maranhão, seja pública ou privada; todos entrevistados são naturais do Maranhão.

\section{Resultados e Discussão}

\subsection{Como aprender - narrativa do médico residente}

A pesquisa foi realizada a partir de oito temas previamente estabelecidos e que orientaram a entrevista com os médicos residentes (porque fazer residência médica, porque escolheu a pediatria, porque escolheu o Hospital Juvêncio Matos (HJM), processo de ensino-aprendizagem na formação do residente, o papel do preceptor, qualidades da residência, dificuldades da residência e preparação do mercado de trabalho).

Os residentes apresentaram uma fala uníssona quanto aos motivos pelos quais optaram por fazer residência médica como forma de complementar sua formação: "só a faculdade não aprofunda conteúdo, queriam ganhar mais segurança na prática médica, acreditam que com a residência melhorariam a assistência ao paciente".

"Quando nós formamos na faculdade, nós estamos aquém de ser médicos. Eu aprendi a ser médica na residência". (R2).

"Na minha opinião, a residência médica deveria ser obrigatória, todo médico deveria fazer residência, eu trabalho fora da residência e eu vejo o tanto de gente que faz besteira num plantão, gente que acabou de sair da faculdade, não sabe nada." (R5).

Estes motivos para ingresso na residência medica corroboram a importância dessa etapa de formação para a consolidação da formação dos médicos.

Em sua dissertação de mestrado, Feuerwerker, explica o porquê da busca do médico recém-formado pela RM:

[...] a insuficiência do treinamento prático proporcionado pelas faculdades de medicina (as novas escolas em função de suas debilidades e as antigas em razão do processo de fragmentação que a formação de graduação vinha sofrendo), e a existência de um mercado de trabalho voltado à especialização e mais competitivo, portanto, foram ingredientes essenciais à multiplicação da procura por vagas de RM. (Camargo \& Feuerwerker, 1997).

Quanto ao motivo de escolher pediatria para fazer residência, a maioria dos residentes teve como argumento a empatia pela especialidade e que os pacientes pediátricos costumam ter boa evolução em casos de doença. Outra motivação pela escolha dessa especialidade foi o baixo quantitativo de profissionais nessa área, alegaram também já ter experiência com crianças, e que são pacientes com poucas comorbidades e que se sentiam mais motivados na pediatria. 
"Os resultados que eu consigo tratando os pacientes pediátricos, comparando com o clínico geral, sempre foram melhores." (R4).

$\mathrm{Na}$ decisão de onde fazer a residência médica, a maioria dos residentes alegou que sua decisão foi baseada na referência de outros residentes que conheciam o serviço em questão. Bons campos de estágios, bons preceptores e poucos residentes foram tópicos também citados nas entrevistas.

"Pessoas que faziam outra residência ou que estavam na residência e falavam sobre o Juvêncio por conta da questão de alguns preceptores, por conta da questão de alguns rodízios, ambulatórios, de questão de UTI, então assim, o Juvêncio me despertou." (R3).

Em relação ao processo de ensino-aprendizagem na formação do residente, todos ressaltaram em sua fala, o empenho de alguns preceptores e a importância da existência de protocolos clínicos em todos os setores do hospital. A maioria dos entrevistados traz também em sua fala que o residente compõe a força de trabalho do hospital, e outros destacam a necessidade de que haja discussão de casos clínicos em todos os cenários de prática.

"Alguns rodízios são mais organizados, tem protocolos clínicos, tem mais cobranças, mais discussão de casos, discussão de parte teórica, outros rodízios não." (R4).

Ainda na questão do processo de ensino-aprendizagem na formação do residente, alguns residentes associaram seu aprendizado à experiência do preceptor, e outros acreditam que seu aprendizado depende do seu próprio interesse.

Considerando a capacitação profissional, em residência médica, segundo Sponholz (2016): "o processo de trabalho, constituindo, antes e acima de tudo, um processo de ensino-aprendizagem, deve colocar o residente diante de situações de atendimento que suscitem a tomada de decisão fundada no conhecimento científico e na experiência médica acumulada com o tempo de prática. Além disso, exige permanente estudo e interlocução com médicos preceptores competentes e experientes. A residência médica deve disponibilizar, para tal, farto contato com os preceptores e horários adequados para atendimento a pacientes, estudo e descanso" (Sponholz et al., 2016).

No que se refere ao papel do preceptor, a maioria dos residentes afirmou ser importante para fomentar discussões de casos, acreditam que uma boa preceptoria melhora o serviço como um todo e que a experiência do preceptor é que faz a diferença no aprendizado, muitos trazem na sua fala que o preceptor serve de exemplo para o residente.

“A gente sempre está se espelhando em alguém, a experiência dos outros conta muito”. (R7).

"Quando tem uma preceptoria boa no serviço é o serviço que melhora, então com isso a gente vai... como se você tivesse mais oportunidade de ver mais casos, discutir mais, te puxa, te instiga, te estimula, então é importante essa retaguarda". (R1).

As concepções defendidas pelos residentes em relação ao papel dos preceptores, reforçam a importância do trabalho destes profissionais para a melhoria da qualidade da residência médica. Os preceptores, na visão dos residentes, atuam como mediadores do processo formativo compartilhando experiências e saberes, servindo de referência profissional e promovendo dessa forma, o aprimoramento profissional dos médicos residentes. 
Castells et al. trazem a importância desse papel do preceptor quando se referem ao "o exercício do preceptor", destacando sua grande importância para que a residência médica, afim de alcançar os objetivos estabelecidos para o novo modelo de formação médica. Dessa forma, é exigido que o preceptor renove, reconstrua, refaça a profissão (Castells, Campos, \& Romano, 2016).

Dentre as qualidades da residência, a maioria dos residentes pontua como importante: o acolhimento pela equipe multiprofissional, a existência de supervisão permanente por parte dos preceptores; citam ainda a existência de bons preceptores, bons campos de estágios e a presença de poucos residentes no serviço como questões importantes. Acreditam que o serviço tem qualidade pela alta rotatividade de pacientes e falam que o serviço está formando bons profissionais.

"Nós somos ativos mesmo, fazemos tudo, discutimos com o preceptor, e sempre nos sentimos responsáveis junto com o preceptor pelo paciente. Isso eu acredito que dá muita confiança pra gente e nos faz ter cada vez mais responsabilidade. A gente tem muito esse aproveitamento prático". (R5).

"Você tem a possibilidade de trabalhar com a supervisão do staff lógico, com a possibilidade de você realizar procedimentos, de você ter contato com muito mais pacientes, então acaba que isso acaba favorecendo nosso aprendizado, fora que o clima dos preceptores que eu passei é muito agradável." (R3).

É possível observar nas proposições apontadas pelos residentes, no que diz respeito às qualidades da residência médica, que o espaço de aprendizagem em que se estabelecem as relações de aperfeiçoamento médico é um espaço em que se destaca por um lado, a prática médica, sempre acompanhada por preceptores experientes e, por outro, o grau de acolhimento.

Dentre as dificuldades da residência, todos os residentes trazem queixa quanto à parte teórica, acreditam que há necessidade de mais aulas teóricas e se queixam da resistência de alguns médicos do serviço quanto à preceptoria. Alguns residentes queixam-se de que os preceptores reclamam da sobrecarga de trabalho; outros citam a queixa de alguns preceptores sobre a falta de remuneração pela preceptoria; alguns outros se queixam da baixa produção científica pelo serviço e acreditam que há necessidade de maior carga horária na atenção primária, sendo que também solicitam melhor campo de estágio de urgência/emergência. Entretanto há queixa também sobre a elevada carga horária executada na residência.

"O que ficou um pouco carente, eu acho, que é a parte teórica, porque assim, nem toda semana a gente consegue ter aula, nem todos os staffs (preceptores) estão acostumados com essa questão de dar aula, tem um e outro que consegue dar aula ou quer dar aula." (R5).

"Alguns chegaram a dizer: 'Ah, eu já não tenho condições de trabalho, já tenho muito serviço, e eu ainda tenho que ficar com residente...', como se fosse assim mais uma preocupação para eles no plantão, no ambiente de trabalho deles". (R2).

As dificuldades destacadas apontam para a necessidade de revisar os processos de ensino e de aprendizagem da residência médica haja vista que sobrecarga de trabalho, deficiência da carga horária teórica, bem como remuneração, são aspectos que dizem respeito tanto à organização pedagógica quanto à organização administrativa da residência.

Tais aspectos precisam ser levados em conta sob o risco de comprometer a qualidade e eficiência desse processo educacional indo de encontro aos pressupostos defendidos na lei n 6.932 de 7 de julho de 1981, que dispõe sobre as atividades da residência médica prevendo uma carga horária de até $20 \%$ para o desenvolvimento de atividades teórico práticas. 
Sobre estar sendo preparado para o mercado de trabalho: a maioria dos residentes fala que se sentem atualmente preparados para qualquer tipo de atendimento, que se sentem preparados para fazer a diferença no SUS. Quanto a trabalhar no interior, falam que não querem trabalhar no interior por falta de estrutura; alguns acreditam ser importante ir para o interior porque precisam fazer a diferença nessas áreas mais carentes. Há também a fala de que possuem mais perfil para atuar junto a paciente hospitalizado.

"Eu não tenho vivência na área privada, mas acho que com a segurança que ganhei na residência posso trabalhar em qualquer lugar: enfermaria, UPA, no interior, sala de parto, ambulatório..." (R4).

"Depois que eu terminar a residência de pediatria, eu também estou disposta a ir pro interior. Eu acho que nós moramos num estado pobre, eu acho que não adianta nós só ficarmos criticando nosso estado e não fazermos nada pra melhorar as condições dele. Então, assim, o sacrificio tem que ser coletivo.” (R2).

\subsection{Como ensinar - narrativa do médico preceptor}

Dentre os preceptores entrevistados, 11 tinham no seu currículo a conclusão de residência médica em pediatria; 9 com subespecialização em UTI pediátrica, UTI neonatal, infectologia pediátrica. Os demais eram preceptores com formação em pediatria geral, lotados na enfermaria ou ambulatório, 1 médico geneticista, 1 médico com especialização em dermatologia pediátrica.

A entrevista foi elaborada a partir de cinco temas amplos (importância do HJM para a pediatria, processo de ensinoaprendizagem na formação do residente, o papel do preceptor, qualidades da residência, dificuldades da residência).

Em relação aos médicos preceptores, todos citaram que o HJM é importante pois funciona como referência para o atendimento em pediatria pelo SUS no estado do Maranhão; a maioria afirmou que o hospital é referência no atendimento pediátrico no estado, e que tem grande potencial de atendimento, funcionando como referência para atendimento de média e baixa complexidade em pediatria no SUS. Preceptores lotados nas unidades de UTIs Neonatal e pediátrica definem o HJM como sendo referência para alta complexidade no estado.

"É um dos principais hospitais de pediatria no maranhão, ele adquiriu uma complexidade muito grande". (P1).

"O Juvêncio é a ponta do sistema de saúde de pediatria do estado, como área mais especializada. Acho que o Juvêncio consegue agregar muitos serviços...” (P2).

Quanto ao processo de ensino-aprendizagem na formação dos residentes, as falas dos preceptores levantaram questões como a necessidade de mais aulas teóricas, o que coincide com a opinião dos residentes; identificamos afirmativas de que a parte prática é intensa no serviço; alguns preceptores acham que certos setores do hospital deixam a desejar quanto ao envolvimento com a RM; alguns preceptores acreditam que deveria ter mais tempo de rodizio na atenção básica; alguns preceptores afirmaram que a formação do residente é responsabilidade do preceptor. Foi citado também a necessidade de qualificação dos médicos preceptores, com participação em cursos de preceptoria médica.

"No Juvêncio a gente está conseguindo mais a parte prática mesmo, é uma deficiência nossa é a parte teórica, é a parte de aula, eu vejo que tem muito pouca. Mas assim, a discussão de casos e o volume de trabalho mesmo, de inserir o residente no serviço tá sendo muito bom". (P3). 
"O serviço em si ele deveria estar mais envolvido com residência quando eu falo serviço eu falo toda equipe, médico, enfermeiro, todos nesse momento mais envolvidos com residência”. (P1).

No que se refere ao papel do preceptor na formação do residente, identificamos que a maioria acredita que os preceptores devem cobrar mais dedicação do residente; acham que o preceptor serve de exemplo para o residente; e a minoria acha que os preceptores têm total responsabilidade na boa formação do residente; alguns afirmaram que esse papel de preceptor deveria ser mais explícito e detalhado quanto a suas responsabilidades.

\footnotetext{
"Não existe uma cobrança em relação ao residente, eu não estou o tempo todo no hospital, mas acho que eles que vão atrás. Eu acho que tem que ter as duas coisas, cobrança e interesse, mas atualmente acho que tem mais interesse". (P1).
}

"Sempre vejo os preceptores abertos a discutir os casos, a conversar com os residentes, a tomar as condutas em conjunto. Mas acho que alguns setores existem colegas que não gostam muito de acompanhar residentes”. (P3).

\begin{abstract}
"O residente está na fase de formação, então temos que ter todo cuidado com eles, é uma responsabilidade muito grande do preceptor, você tentar ensinar o que é correto para ele sair daqui e fazer o que é correto, e eu tento estimular eles a estudar os casos". (P3).
\end{abstract}

Percebemos em algumas falas, dos preceptores, que existe dúvida quanto ao seu papel, e quais seriam as possíveis diferenças com o papel do médico assistente. De fato ainda existem dúvidas sobre: a quem cabe a preceptoria e quais seriam suas responsabilidades, e qual seria o papel dos demais médicos assistentes do serviço, considerando que o Secretaria de Saúde do Estado do Maranhão, tomou a iniciativa de estabelecer uma bolsa para um número especifico de médicos que exerceriam papel de preceptores para incentivar o acompanhamento desses médicos residentes, garantindo sua formação adequada haja vista muitas queixas em outras residência médicas no Estado. Iniciativa essa inovadora, considerando não haver na maioria dos estados nenhuma política pública de incentivo à preceptoria.

Para que o processo de trabalho do qual participa o médico residente constitua, antes e acima de tudo, um processo de ensino-aprendizagem, ele não pode prescindir da presença, da competência, da experiência e do exemplo dos médicos preceptores no atendimento aos pacientes (Sponholz et al., 2016).

O preceptor do residente desempenha a função de docência específica e diretamente relacionada aos residentes sob sua supervisão. Desta forma, mostra-se importante a existência de políticas de valorização desses profissionais, objetivando sua fixação na RM para a ampliação do número de vagas e maior contribuição acadêmica e científica (Fontenelle \& Brandão, 2018).

Em relação às qualidades da residência, em suas falas, a maioria dos preceptores reafirmou a importância de ter muita prática no serviço, pontuaram a "diversidade de atendimento do serviço, com diversas especialidades nos ambulatórios, existência de UTIs pediátrica e neonatal. Alguns citam que o hospital é referência aos procedimentos de média complexidade, mas que também tem alta complexidade, o que é uma qualidade na formação dos residentes; e afirmaram que o serviço está conseguindo formar bons profissionais na sua opinião, e que isso é uma qualidade. 
"A diversidade do serviço, a complexidade... Eles podem ter contato com vários tipos de doenças, de pacientes. Não falta paciente para eles. Tem uma diversidade de setores, mas poderia ter mais. Eu acho assim que o hospital oferece um serviço de qualidade". (P1).

"No HJM tem muitas opções de rodízios, muitas possibilidades com muitos profissionais, por exemplo ambulatórios de pediatria geral, ambulatórios de especialidades, alojamento conjunto, uti pediátrica e neonatal, eles têm um leque de aprendizado muito grande, tem muito volume”. (P2).

Na visão dos preceptores, a residência médica constitui um importante espaço de desenvolvimento profissional.

Entre as dificuldades da residência, identificamos nas falas dos preceptores questão poucas aulas teóricas, o que coincide com a fala dos residentes. Citam ainda a sobrecarga de trabalho, e que isso dificulta ou atrapalha sua participação na formação do residente. Pontuam a falta de qualificação em preceptoria para muitos médicos do serviço, e alguns se queixam da estrutura física, por ser um hospital antigo, necessitando de reformas e adaptações.

Afirmam ainda que a residência se baseia num modelo hospitalocêntrico e na sua opinião isso é uma dificuldade na formação do residente, e que há necessidade de mais médicos no hospital, e consequentemente mais preceptores.

"Deveria ter melhores preceptores, eu acho que é um problema que não é só de lá. Só ia mudar se tivesse uma estratégia, uma política de discussão de casos, de ter cursos, atualizações, de trazer profissionais de fora para atualização da equipe". (P1).

"Nem sempre o médico está preparado para fazer essa supervisão. Nem todo mundo que tem conhecimento sabe transmitir, tem gente que têm conhecimento, mas não quer ensinar, tem médico que não quer ficar com o residente". (P2).

É importante destacar que os preceptores apontam questões de suma importância para a garantia da eficiência e eficácia do programa de residência médica. Questões essas que envolvem tanto condições estruturais quanto o processo de formação continuada. Nesse sentido, ressaltamos a importância da Escola de Saúde do Estado, nessas questões.

\section{Considerações Finais}

As falas de médicos preceptores e médicos residentes acerca da Residência Médica em Pediatria apontou algumas questões intrigantes, sobretudo a importância e responsabilidade, unânime, sobre o papel do preceptor. Ele é avaliado pelos dois grupos como responsável pelo aprendizado do que- fazer- médico. Figura determinante neste aprendizado, o seu empenho é que movimenta a teoria aprendida em função da necessidade de intervenção do médico pediatra, e refaz a própria profissão, segundo relato de residente.

Ele é um ideal do eu para os residentes, um modelo a ser seguido, e cuja competência clínica, reconhecida na equipe multiprofissional do hospital, tem poder para influenciar, inclusive, a qualidade do acolhimento aos residentes sob determinadas preceptorias. A presença do preceptor domina todo o processo de ensino-aprendizagem, obscurecendo parcialmente as aulas teóricas, embora haja queixas quanto à quantidade e qualidade delas, por vezes não aceitas pelos preceptores como sendo de sua responsabilidade. Paradoxalmente a tamanho impacto, muitos preceptores parecem não perceber esta importância fundamental, negando-se a aulas e supervisões de residentes, através de explicações mais afeitas à gestão e à remuneração, como sobrecarga no plantão e ausência de gratificação para esta função. Os preceptores solicitam 
curso de preceptoria, que parece aproximar-se mais às questões administrativas, de gestão e didáticas, do que propriamente, ao conteúdo técnico da profissão.

A escolha pela especialidade de pediatria remete a um certo grau de êxito de intervenção clínica, visto que são pacientes com menos comorbidades, melhor evolução, que produzem mais motivação também, além de haver menos especialistas nesta área.

O HJM é considerado por ambos os grupos um bom campo de prática para treinamento em serviço, porque faz rodízio entre os cenários de ambulatório e de alta complexidade como o UTI, tem bons preceptores, bom nível de acolhimento, tem discussão de caso clínico e obedece a protocolos em pediatria. Entretanto a residência ainda é considerada hospitalocêntrica e há observação sobre a baixa carga horária na UBS. Merece registro o relato de que há preceptores que não obedecem aos protocolos de conduta clínica em pediatria, cuja orientação é baseada na medicina por evidência científica. Há queixa de baixa pesquisa e pouca produção científica na residência. Um médico, com 06 anos de formação ainda é considerado pelos próprios residentes como "ainda não médico", condição a ser superada somente após mais 02 anos de aprendizado em residência médica, o que deveria remeter a profundas reflexões sobre ensino em nosso país.

$\mathrm{Na}$ decisão de ir trabalhar no interior do estado após a residência, os residentes utilizam-se quase que do mesmo argumento, para ir e para ficar. Ir para o interior porque é necessário fazer a diferença no SUS, sistema amplo, porém com muitas deficiências inclusive materiais; não ir para o interior, exatamente porque o SUS tem muitas deficiências, inclusive materiais.

Com o resultado da nossa pesquisa, como forma de contribuição, o produto técnico, aponta algumas proposições, tendo em vista a melhoria no programa de Residência Médica de Pediatria da rede de Saúde do Estado do Maranhão.

Dentre essas preposições destacamos: a implementação de cursos de formação de preceptores a cada ciclo de residência médica; a garantia de protocolos clínicos em todas os hospitais escola; a inclusão do processo avaliativo dos preceptores pelos residentes e a elaboração de um manual do preceptor (remunerados e não remunerados) em que estejam delineadas suas competências pedagógicas e responsabilidades técnicas. Considerando que cabe à Escola de Saúde sugerir a constituição de uma Comissão formada por técnicos dessa escola para discutir as fragilidades do Programa de Residência Médica em Pediatria. A partir dessas discussões, elaborar uma proposta que minimize e impacte positivamente o programa.

\section{Referências}

Brasil. Lei n ${ }^{\circ}$ 8.080, Diário Oficial da União, Brasília (DF) (1990). http://www.planalto.gov.br/ccivil_03/leis/18080.htm

Brasil. Resolução $n^{\circ} 3$ de 20 de junho de 2014., Diário Oficial da União § (2014). www.abmes.org.br

Brasil, S. F. Constituição da Republica Federativa do Brasil (1988). https://doi.org/10.4304/jcp.6.9.1903-1912

Camargo, L., \& Feuerwerker, M. (1997). Mudanças na educação médica e residência. https://doi.org/10.11606/D.6.2018

Castells, M. A., Campos, C. E. A., \& Romano, V. F. (2016). Residência em Medicina de Família e Comunidade: Atividades da Preceptoria. Revista Brasileira de Educação Médica, 40(3), 461-469. https://doi.org/10.1590/1981-52712015v40n3e02862014

Ceccon, R. F., Bueno, A. L. M., Hesler, L. Z., Kirsten, K. S., Portes, V. de M., \& Viecili, P. R. N. (2014). Mortalidade infantil e Saúde da Família nas unidades da Federação brasileira, 1998-2008. Cadernos Saúde Coletiva, 22(2), 177-183. https://doi.org/10.1590/1414-462x201400020011

Fernandes, C. R., Sousa, R. Q. de, Arcanjo, F. S. A., Neto, G. C. de M., Gomes, J. M. A., \& Giaxa, R. R. B. (2015). Implantação de residência em anestesiologia no interior do Nordeste do Brasil: Impacto nos processos de trabalho e na motivação profissional. Revista Brasileira de Anestesiologia, 65(2), 155-161. https://doi.org/10.1016/j.bjan.2013.08.006

Fontenelle, L. F., \& Brandão, D. J. (2018). Uma proposta metodológica para a elaboração de revisões clínicas. Revista Brasileira de Medicina de Família e Comunidade, 13(40), 1-10. https://doi.org/10.5712/rbmfc13(40)1871

Maranhão, S. L. Lei Ordinária nº 11.114, de 2 de outubro de 2019 (2019).

Minayo, M. C. de S. (2013). Hermenêutica-dialética como caminho do pensamento socialNo Title. In Caminhos do pensamento: epistemologia e método (Fiocruz, p. 380). Rio de janeiro. 
Research, Society and Development, v. 10, n. 5, e20510514868, 2021

(CC BY 4.0) | ISSN 2525-3409 | DOI: http://dx.doi.org/10.33448/rsd-v10i5.14868

Minayo, M. C. de S. (2014). O desafio do conhecimento: pesquisa qualitativa em saúde. (Hucitec, Org.) (14a ed).

Petta, H. L., Lima, R. de Q. P. V. V., Oliveira, S. M. dos S. F. P. M. S. de, \& Gomes, E. C. O. R. R. (2017). Preceptoria de Residência Médica no SUS. Projetos de Apoio ao SUS.

Scheffer, M., Cassenote, A., Poz, M. R. D., Matijasevitch, A., \& Castilho, E. A. de. (2015). Demografia Médica no Brasil 2015. Conselho Federal de Medicina (CFM) e Conselho Regional de Medicina do Estado de São Paulo (Cremesp). http://www.usp.br/agen/wpcontent/uploads/DemografiaMedica30nov20153.pdf

Sponholz, T. C. H., Sartori, M. T., Marques, A. P. S., Albuquerque, G. S. C. de, Silva, M. J. de S., \& Perna, P. de O. (2016). Processo De Trabalho Na Residência Médica: a Subordinação Do Ensino-Aprendizagem À Exploração Da Força De Trabalho Dos Residentes. Trabalho, Educação e Saúde, 14(suppl 1), 67-87. https://doi.org/10.1590/1981-7746-sol00025

Teixeira, P. R., Gonsalez, E. G., Rotta, D. S., Pinto, M. H., Peres, L., \& Beretta, D. (2017). Pediatria Work Engagement Among Pediatric Physician Residents. Revista Brasileira de Educação Médica, 41(1), 126-133.

World Health Organization. (2008). Estatísticas sobre gênero e força de trabalho em saúde. Spotlight. 